\title{
CITYBEM: AN OPEN SOURCE IMPLEMENTATION AND VALIDATION OF MONTHLY HEATING AND COOLING ENERGY NEEDS FOR 3D BUILDINGS IN CITIES
}

\author{
S. M. Murshed ${ }^{\text {a }}$, S. Picard ${ }^{\text {b }}$, A. Koch ${ }^{\text {a }}$ \\ ${ }^{a}$ European Institute for Energy Research, Emmy-Noether Str. 11, 76131 Karlsruhe, Germany - (murshed, koch)@eifer.org \\ ${ }^{\mathrm{b}}$ École Supérieure d'Électricité, 3 Rue Joliot Curie, 91190 Gif-sur-Yvette, France - solene.picard@ supelec.fr
}

KEY WORDS: Building energy modelling, Heating and cooling needs, 3D city model, Validation, Python, TRNSYS

\begin{abstract}
:
Cities play an important role in reaching local and global targets on energy efficiency and the reduction of greenhouse gas emissions. In order to determine the potential of energy efficiency in the building sector new planning instruments are required that allow depicting the complete building stock on the one hand and investigate detailed measures on the other hand. To pursue this objective, the ISO 13970:2008 monthly heating and cooling energy model is implemented using an open source based software architecture (CityBEM), in connection with data from 3D city models in the CityGML standard (LOD2). Input parameters such as the building geometry, typology and energy characteristics have been associated with the 3D data. The model has been applied to several urban districts with different numbers of buildings in the city of Karlsruhe. In order to test the accuracy of the implemented model and its robustness, a 3-step validation has been conducted. The comparison of simulation results with results based on a TRNSYS simulation showed acceptable results for the studied application cases. The proposed approach can help urban decision makers to perform a city or district wide analysis of the building energy need which can be further used to prepare future scenarios or renovation plans to support decision making.
\end{abstract}

\section{INTRODUCTION}

Building energy modelling (BEM) and their implementation at various spatial and temporal scales have been performed for a number of years. Statistical and engineering models are used for a multitude of applications (Swan and Ugursal 2009). Use cases include the definition of low carbon energy strategies (Nouvel et al. 2015), increasing the energy efficiency for building refurbishment plans (Bahu et al. 2014), etc. Statistical methods are highly dependent on historical data of energy use, whereas engineering models are based on the physical properties of buildings and heat transfer calculations. The advantages and disadvantages for such modelling approaches at the scale of neighbourhoods are reviewed for example by Koch (2016), Chalal et al. (2016), Reinhart and Davila (2016) or Mendes, Ioakimidis and Ferrão (2011).

\subsection{Application of the ISO 13790:2008 standard}

ISO 13970:2008 standard provides a deterministic model to calculate heating and cooling energy needs (ISO 2008). It is one of a series of calculation methods for the design and evaluation of energy performance of buildings. Energy needs for space heating and cooling of buildings are calculated on the basis of the heat balance of the building zone at three different temporal resolutions: hourly, monthly and seasonal. Many studies have applied this approach with different assumptions and contexts. Several national authorities have also adopted a performance-based method using a monthly energy balance, for example Romania (Attia and Ana Muresan 2015) or South Korea (Kwak, Jo and Suh 2015). Vollaro et al. (2014) calculated the monthly cooling and heating energy performance of an old building in central Italy using the ISO 13970 based software named MC11300. The results were validated with the dynamic simulation software (TRNSYS). Kim, Yoon and Park (2013) compared the simplified ISO 13970 method and dynamic (EnergyPlus software) simulation approach with regard to uncertainty. The different simulations are tested on a general five-storey office building in the South Korea. They highlighted the importance of calibration for unknown parameters (numerical parameters and time constants) in a local application of the ISO 13790 monthly method. Kristensen and Petersen (2016) gave an overview of existing sensitivity analyses for building energy modelling (Local, Morris and Sobol' methods). In this regard, they investigated the monthly and the hourly ISO 13790 methods considering a building zone test case located in Denmark. Kokogiannakis , Strachan and Clarke (2008) carried out a comparative analysis of the hourly and monthly ISO 13790 method with simulation programs (e.g. ESP-r and EnergyPlus). Several parameters of a typical office building are varied by considering different climate, internal heat gains, glazing areas, ventilation schedules, etc. Corrado and Fabrizio (2007) proposed a useful implementation of the ISO 13790 monthly method, in particular to supply a formulation of the dynamic parameters and adapt them to the local climate. The simulation was performed on some real buildings in Italy, assuming different climatic conditions. The method is then validated with EnergyPlus. Within the framework of a EU project ENTRANZE (Zangheri et al. 2014), cooling and heating energy demand of four different building types across 10 European cities (Seville, Madrid, Rome, Milan, Bucharest, Vienna, Paris, Prague, Berlin and Helsinki) were performed by EnergyPlus simulation software. The results were compared with the ISO 13790 hourly (implemented in spreadsheet) and ISO 13790 monthly (INVERT/EE-Lab program) method. They concluded that due to different calculation approaches and different degrees of complexities of

\footnotetext{
* Corresponding author
} 
the building and usage description in the three simulation tools, the energy needs varied significantly.

Furthermore, Sirén and Hasan (2007) applied the hourly and monthly methods using a model office building in Finland. The results were validated with the IDA-ICE building energy software, considering it as a reference. Vartieres, Berescu and Damian (2013) applied three different modelling approaches (e.g. ISO 13970 monthly, CODYBA and TRNSYS) to calculate the cooling energy demand of an office building in Bucharest. Then a comparative assessment on the modelling input parameters and results was performed. Table 1 provides an overview on some of the cited applications.

\begin{tabular}{|l|l|l|l|}
\hline Reference & $\begin{array}{l}\text { Type of } \\
\text { building }\end{array}$ & Method & Validation \\
\hline $\begin{array}{l}\text { (Vollaro et } \\
\text { al. 2014) }\end{array}$ & $\begin{array}{l}\text { Old building } \\
\text { (Central Italy) }\end{array}$ & $\begin{array}{l}\text { MC11300 based on } \\
\text { ISO 13790 monthly } \\
\text { method (heating, } \\
\text { cooling) }\end{array}$ & TRNSYS \\
\hline $\begin{array}{l}\text { (Vartieres } \\
\text { et al. 2013) }\end{array}$ & $\begin{array}{l}\text { Office building } \\
\text { (Bucharest) }\end{array}$ & $\begin{array}{l}\text { Monthly method } \\
\text { same as ISO 13790 } \\
\text { CODYBA (cooling) }\end{array}$ & TRNSYS \\
\hline $\begin{array}{l}\text { (Kim et al. } \\
\text { 2013) }\end{array}$ & $\begin{array}{l}\text { Office building } \\
\text { (South Korea) }\end{array}$ & $\begin{array}{l}\text { Monthly ISO 13790 } \\
\text { (cooling, heating) }\end{array}$ & EnergyPlus \\
\hline $\begin{array}{l}\text { (Kokogian } \\
\text { nakis et al. } \\
\text { 2008) }\end{array}$ & $\begin{array}{l}\text { Office building } \\
\text { (Amsterdam } \\
\text { Athens) }\end{array}$ & $\begin{array}{l}\text { Monthly and hourly } \\
\text { ISO 13790 } \\
\text { (cooling, heating) }\end{array}$ & EnergyPlus \\
\hline $\begin{array}{l}\text { (Zangheri } \\
\text { et al. 2014) }\end{array}$ & $\begin{array}{l}\text { types of } \\
\text { building (10 } \\
\text { cities in Europe) }\end{array}$ & $\begin{array}{l}\text { Hourly ISO 13790 } \\
\text { (Spreadsheet) and } \\
\text { monthly ISO 13790 } \\
\text { (cooling, heating) }\end{array}$ & EnergyPlus \\
\hline $\begin{array}{l}\text { (Corrado } \\
\text { and } \\
\text { Fabrizio } \\
\text { 2007) }\end{array}$ & $\begin{array}{l}\text { Single family, } \\
\text { multi-family, } \\
\text { office (Italy) }\end{array}$ & $\begin{array}{l}\text { Monthly method } \\
\text { from ISO 13790 } \\
\text { (cooling, heating) }\end{array}$ & EnergyPlus \\
\hline $\begin{array}{l}\text { (Kwak et } \\
\text { al. 2015) }\end{array}$ & $\begin{array}{l}\text { Seoul (South } \\
\text { Korea) }\end{array}$ & $\begin{array}{l}\text { Monthly method } \\
\text { ISO 13790 } \\
\text { (heating, cooling) }\end{array}$ & EnergyPlus \\
\hline
\end{tabular}

Table 1. Literature review on the use of ISO 13970 method

All these studies have calculated the energy need for one building at a time, considering required model inputs e.g., solar radiations, floor areas and volumes, etc. With the availability of standardized 3D city models e.g. in CityGML format, (OGC 2012) and of different levels of details (LOD1, LOD2, etc.) across many cities in the world, the building energy related characteristics can accurately be calculated. Many recent studies have pointed out the potential for such applications (Biljecki et al. 2015; Bahu et al. 2014), but only few studies have considered the 3D building characteristics as inputs into the ISO method to analyse heating and cooling energy needs for a large number of buildings in a district or a city. Chalal et al. (2016) performed a critical literature review of mainly 2D and 3D GIS based approaches for energy prediction models. (Eicker et al. 2012) calculated the monthly heat demand in three districts in Germany using the 3D city models and applying the German standard DIN 18599. Later (Nouvel et al. 2013) implemented the monthly ISO 13970 method with the 3D buildings data to calculate heating energy needs in the two residential districts in Karlsruhe (LOD1) and Ludwigsburg (LOD2). Recently, Nouvel et al. (2015) attempted to combine a statistical and engineering modelling approaches to ascertain the building heating needs in order to support urban energy policies on buildings. Agugiaro (2016) calculated the residential energy demand for both space heating and hot water following the simplified calculation procedure, as described by the Technical Specification UNI/TS 11300:2008-National annex to CEN standards (parts 1 and 2) in Italy. In this regard, the LOD2 data of the part of city of Trento was chosen as the study area. However, no validation was performed.

\subsection{Research gaps}

Based on the literature review on the use of ISO 13970:2008 standard, we observe that simulation was mostly performed on individual buildings. Some tools and software were developed for specific purposes and few open source implementations were realized. Some recent studies have adopted the 3D city models to assess energy needs based on country specific norms in some particular sectors (e.g., residential buildings). None of them performed for both heating and cooling energy need. Some 3D city model based studies performed validation of ISO method using consumption data; others did not perform robust validation of their implementation. A model should be validated against another model.

\subsection{Main objectives}

Considering the research gaps, the main objectives of this paper are to (a) implement the ISO method using the 3D city models to calculate the building heating and cooling energy needs on monthly basis, (b) develop the CityBEM model- considering the open source software implementation to carry out a quick and robust analysis, (c) consider 3D buildings (building geometry and attributes) at a district or city and use publicly available datasets, (d) perform a 3-step validation of the CityBEM model and (e) allow 3D visualization and perform statistical analysis.

In Chapter 2, a short description of the ISO 13970 method is given. The implementation of the method i.e. required data, modelling steps, etc. is explained in Chapter 3. Then Chapter 4 explains the results and visualizes the main findings in 3D environment. Afterwards, a 3-step validation is performed in Chapter 5. Finally, a conclusion by highlighting the limitation and future development of the CityBEM model is drawn in Chapter 6.

\section{DESCRIPTION OF METHOD}

\subsection{Monthly ISO 13970:2008 method}

The monthly method is developed at a macroscopic level of thermal gains and losses and is based on the simplified representation of building physics. It takes into account dynamic effects by empirically determined utilization factors ${ }^{1}$ for heat losses or gains. The model calculates heating or cooling monthly energy demands, based on the balance between (a) the transmission and ventilation heat losses and (b) the internal and solar gains, in interaction with the building mass, external factors and occupant's behaviour (ISO 2008).

The method is used worldwide by different national energy standard organizations and the results are proved to be accurate and robust in long term urban energy scenario development for a district having hundreds of buildings (Nouvel et al. 2015). Advantages are highlighted in several literatures e.g. (Kim et al. 2013), (ISO 2008), etc. The monthly ISO model also produces good results compared to other software such as EnergyPlus (Kristensen and Petersen 2016). It is also proved that this simplified quasi-steady state monthly method is able to predict year-round energy needs considering that the dynamic

\footnotetext{
${ }^{1}$ Utilization factor is a function mainly of the heat-balance ratio and the thermal inertia of the building (ISO 2008).
} 
parameters are correctly determined (Corrado and Fabrizio 2007).

\subsection{Main structure}

The ISO 13970 monthly method is mainly structured into 4 main blocks: (a) definition of building boundaries for conditioned and unconditioned spaces (b) identification of the zones (single vs. multi zones ${ }^{2}$ ) (c) definition of the internal conditions for calculation of external climate, and other environmental data inputs (heat transfer losses, heat gain, etc.) (d) calculation of energy needs for heating and cooling, for each time step and building.

\section{IMPLEMENTATION OF THE METHOD}

\subsection{Software architecture}

Several software and tools are required for the implementation and the analyses of the monthly energy need of the 3D building. They are mainly open source and freely available (Figure 1).

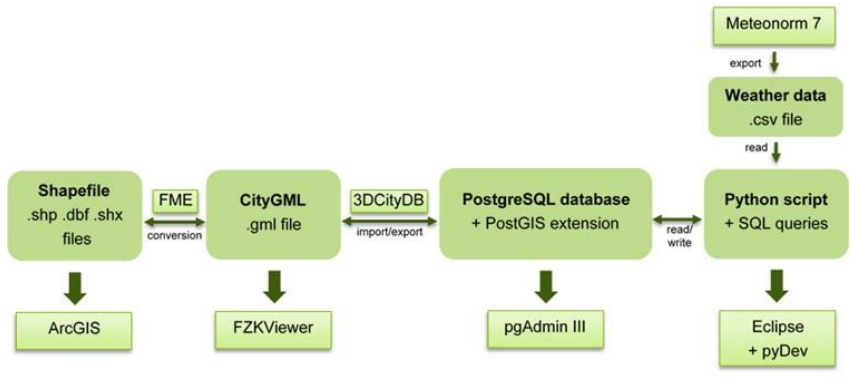

Figure 1. Overview of different software and tool to implement the monthly ISO method into the 3D environment

Eclipse is an integrated development environment used in computer programming, which contains a base workspace and an extensible plug-in system for customizing the environment. For this study, the PyDev plug-in (http://www.pydev.org) is used to work with Python scripts. Python supports connection to the PostgreSQL database (https://www.postgresql.org). Queries to the database are written in SQL language between quotation marks into the Python script. pgAdmin III- an open source administration and development platform for PostgreSQL object-relational database is also used. Moreover, to treat the spatial data such as CityGML, the PostGIS extension is used to support to PostgreSQL database.

The 3DCityDB (http://www.3dcitydb.org/3dcitydb) is a free open source package consisting of a database schema and a set of software tools to import, manage, analyze, visualize, and export virtual 3D city models according to the CityGML standard. This software includes a tool for importing CityGML data into a PostgreSQL database. The software FZKViewer (https://www.iai.kit.edu/1302.php) is used to visualize and inspect CityGML data. QGIS is an open source Geographic Information System (GIS) application that provides data viewing, editing, and analysis. This software supports connection to PostgreSQL database. Finally, ArcScene is used to visualize the monthly energy need results in the 3D environment. The Feature Manipulation Engine (FME) is used to translation of spatial data e.g. conversion between shapefile and CityGML. The Meteonorm 7.1 software $^{3}$ is used to collect

\footnotetext{
${ }^{2}$ A multi-zone is composed of a multiple indoor units and an outdoor unit, whereas a single zone consists of one indoor unit.

${ }^{3} \mathrm{http}: / /$ www.meteonorm.com/de/downloads
}

the weather data on monthly average temperature and wind speed.

\subsection{Required input data and data handling}

The ISO 13790:2008 monthly method mainly requires three categories of input data for modelling building monthly energy needs (Table 2).

\begin{tabular}{|c|c|c|}
\hline Input data & Unit & Source \\
\hline \multicolumn{3}{|l|}{ a. Building geometry } \\
\hline Wall North & $\mathrm{m}^{2}$ & CityGML data \\
\hline Wall South & $\mathrm{m}^{2}$ & CityGML data \\
\hline Wall East & $\mathrm{m}^{2}$ & CityGML data \\
\hline Wall West & $\mathrm{m}^{2}$ & CityGML data \\
\hline Volume & $\mathrm{m}^{3}$ & CityGML data \\
\hline $\begin{array}{l}\text { Floor area/conditioned used } \\
\text { area }\end{array}$ & $\mathrm{m}^{2}$ & $\begin{array}{l}\text { Calculated from EnEV } \\
2015 \text { and volume }\end{array}$ \\
\hline Effective mass area & $\mathrm{m}^{2}$ & $\begin{array}{l}\text { Calculated from the floor } \\
\text { area ((ISO 2008), p. 66-68) }\end{array}$ \\
\hline \multicolumn{3}{|l|}{ b. Building typology } \\
\hline Windows North & $\%$ & Energy concept advisor ${ }^{4}$ \\
\hline Windows South & $\%$ & Energy concept advisor \\
\hline Windows East & $\%$ & Energy concept advisor \\
\hline Windows West & $\%$ & Energy concept advisor \\
\hline U-value wall & $\mathrm{W} / \mathrm{m}^{2} \mathrm{~K}$ & ÎWU ${ }^{5}$ \\
\hline U-value roof & $\mathrm{W} / \mathrm{m}^{2} \mathrm{~K}$ & IWU \\
\hline U-value ground & $\mathrm{W} / \mathrm{m}^{2} \mathrm{~K}$ & IWU \\
\hline U-value windows & $\mathrm{W} / \mathrm{m}^{2} \mathrm{~K}$ & IWU \\
\hline g-value windows & & IWU \\
\hline Thermal bridges & $\mathrm{W} / \mathrm{m}^{2} \mathrm{~K}$ & IWU \\
\hline Infiltration & $1 / \mathrm{h}$ & IWU \\
\hline Ventilation & $1 / \mathrm{h}$ & IWU \\
\hline Internal heat from occupants & $\mathrm{W} / \mathrm{m}^{2}$ & IWU \\
\hline Internal heat from appliances & $\mathrm{W} / \mathrm{m}^{2}$ & IWU \\
\hline Internal heat from lighting & $\mathrm{W} / \mathrm{m}^{2}$ & IWU \\
\hline \multicolumn{3}{|l|}{ c. Weather conditions } \\
\hline $\begin{array}{l}\text { Monthly temperature of the } \\
\text { external environment }\end{array}$ & ${ }^{\circ} \mathrm{C}$ & Meteonorm (TMY3) \\
\hline Monthly wind speed & $\mathrm{m} / \mathrm{s}$ & Meteonorm (TMY3) \\
\hline Monthly solar irradiance & $\mathrm{W} / \mathrm{m}^{2}$ & Solar radiation model \\
\hline
\end{tabular}

Table 2. Required input data and corresponding source for the CityBEM monthly model

Data on building geometry is collected in 3D CityGML format (LOD2), which allows identification of individual walls, roofs or floor surfaces and thus allows calculation of conditioned floor area and building volume. Data on building typology describes the building attributes e.g. building type (single family house, apartment block, etc.), building age as well as building energetic characteristics such as $U$ values, g-values, etc. They are collected from the typologies defined by the EU funded project Energy Concept advisor and the Institut Wohnen und Umwelt. The data on weather conditions such as monthly average temperature and wind speed data is collected from the Meteonorm 7.1 software as TMY3 format. The average monthly solar radiation for every building surface is calculated from a solar radiation model, which takes the shading of the buildings into account.

LOD2 CityGML data on building is imported into the Postgres/CityDB database with information about the geometry and the building coordinates. Then, using the python script, surface and volume of each building is calculated within the eclipse environment. Building typology data datasets are

\footnotetext{
${ }^{4}$ http://www.district-eca.de

5 Institut Wohnen und Umwelt GmbH (Institute for housing and environment, http://www.iwu.de/home/)
} 
collected in excel or csv format. All these datasets are processed using python scripts and are stored as different tables in the PostgreSQL database (Figure 1).

\subsection{Calculation steps}

For each building and each month, the energy needs for heating and cooling are calculated in accordance with the suggestions provided by the ISO method. However, some key assumptions are made e.g., (a) each building is modelled as single zone, (b) The set-point temperatures, internal gains and air change rates are averaged according to the respective conditioned used area and (c) Reduction factor is taken into account for calculating intermittence heating and cooling need.

The CityBEM model is implemented in 7 main steps (Figure 2):

1. Calculation of heat transfer coefficient by transmission $\left(H_{t r}\right)$ and ventilation $\left(H_{v e}\right)$

2. Calculation of the total heat transfer $\left(Q_{h t}\right)$ assuming the time step $t$ of one month

$$
Q_{h t}=Q_{t r}+Q_{v e}=\left(H_{t r}+H_{v e}\right) \cdot\left(\theta_{i n t, s e t}-\theta_{e}\right) \cdot t
$$

3. Calculation of heat flows coefficient from solar radiations $\left(\phi_{\text {sol }}\right)$ and internal sources $\left(\phi_{\text {int }}\right)$

4. Calculation of total heat gains $\left(Q_{g n}\right)$ from the internal and solar heat gains, assuming the time step $t$ of one month

$$
Q_{g n}=Q_{i n t}+Q_{s o l}=\left(\Phi_{i n t}+\Phi_{\text {sol }}\right) \cdot t
$$

5. Calculation of the dynamic parameters: $\eta_{l s}$ utilization factor for heat losses (cooling mode), $\eta_{g n}$ utilization factor for heat gains (heating mode)

6. Reduction factor for intermittent cooling $\left(a_{C, r e d}\right)$ and heating $\left(a_{H_{2} r e d}\right)$

7. Calculation of cooling and heating need: For the cooling mode:

$$
\begin{gathered}
Q_{C, \text { nd }}=Q_{g n}-\eta_{l s} \cdot Q_{h t} \\
Q_{C, \text { nd }, \text { interm }}=a_{C, \text { red }} \cdot Q_{C, n d}
\end{gathered}
$$

For the heating mode:

\begin{tabular}{|c|c|c|}
\hline Variable & Unit & Definition \\
\hline$H_{t r}$ and $H_{v e}$ & $\mathrm{~W} / \mathrm{K}$ & $\begin{array}{l}\text { Heat transfer coefficient by } \\
\text { transmission and ventilation }\end{array}$ \\
\hline$\Phi_{\text {int }}$ and $\Phi_{\text {sol }}$ & W & $\begin{array}{l}\text { Heat flows coefficient from internal } \\
\text { sources and solar radiations }\end{array}$ \\
\hline$Q_{h t}$ & MJ & $\begin{array}{l}\text { Total heat transfer (by transmission } \\
\text { and ventilation) }\end{array}$ \\
\hline$Q_{g n}$ & MJ & $\begin{array}{l}\text { Total heat gains (solar and internal } \\
\text { gains) }\end{array}$ \\
\hline $\mathrm{t}$ & Month & Time step is expressed in megasecond \\
\hline$\eta_{l s}$ & - & Utilization factor for heat losses \\
\hline$\eta_{g n}$ & - & Utilization factor for heat gains \\
\hline$a_{C \text { red }}$ & - & Reduction factor for cooling \\
\hline$a_{H, \text { red }}$ & - & Reduction factor for heating \\
\hline$Q_{C, \text { nd }}$ & MJ & $\begin{array}{l}\text { Energy need for the continuous } \\
\text { cooling mode }\end{array}$ \\
\hline$Q_{H_{2} \text { nd }}$ & MJ & $\begin{array}{l}\text { Energy need for the continuous } \\
\text { heating mode }\end{array}$ \\
\hline$Q_{C, \text { nd,interm }}$ & MJ & $\begin{array}{l}\text { Energy need for the intermittent } \\
\text { cooling mode }\end{array}$ \\
\hline$Q_{H_{l} \text { nd,interm }}$ & MJ & $\begin{array}{l}\text { Energy need for the intermittent } \\
\text { heating mode }\end{array}$ \\
\hline
\end{tabular}

$$
\begin{gathered}
Q_{H, n d}=Q_{h t}-\eta_{g n} \cdot Q_{g n} \\
Q_{H, n d, \text { interm }}=a_{H, \text { red }} \cdot Q_{H, n d}
\end{gathered}
$$

Where,
The calculation steps and equations are also implemented in the Eclipse using python scripts, PostgreSQL and other related tools. Several scripts and functions are written in modular structure. They are divided into 10 packages, which allows inspection of intermediate results of the individual model components. The intermediate results and final outputs the monthly cooling and heating energy needs are also saved as tables in the database from where automatized graphs are prepared. The database is connected with QGIS to visualize the results in $2 \mathrm{D}$ and is also exported to ArcScene for visualization in $3 \mathrm{D}$ environment.

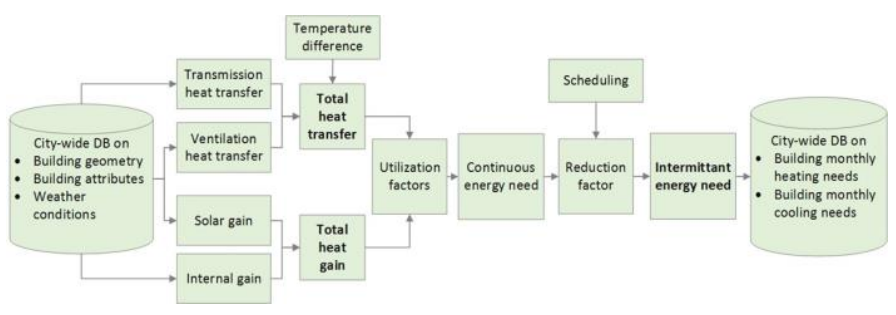

Figure 2. Implementation steps of the CityBEM monthy model for building energy need calculation

\section{DISCUSSION AND VISUALIZATION OF RESULTS}

One of the main objectives of this study is to apply the CityBEM model in a case study region to perform building heating and cooling energy needs in a city or a district. Therefore, the model is tested on different number of building stocks (using both LOD1 and LOD2 data) in different cities. This paper mainly explains the application in the city of Karlsruhe, Germany on about 4300 buildings (LOD2).

The yearly specific heating energy needs of the individual buildings ranges from about 15 to $510 \mathrm{kWh} / \mathrm{m}^{2} /$ year, depending on the characteristics and thermal behaviour of the building as well as the local weather conditions (Figure 3). The cooling energy need is rather low, because of the moderately cooler climatic conditions in the study region. It is between 0 and 50 $\mathrm{kWh} / \mathrm{m}^{2} /$ year.

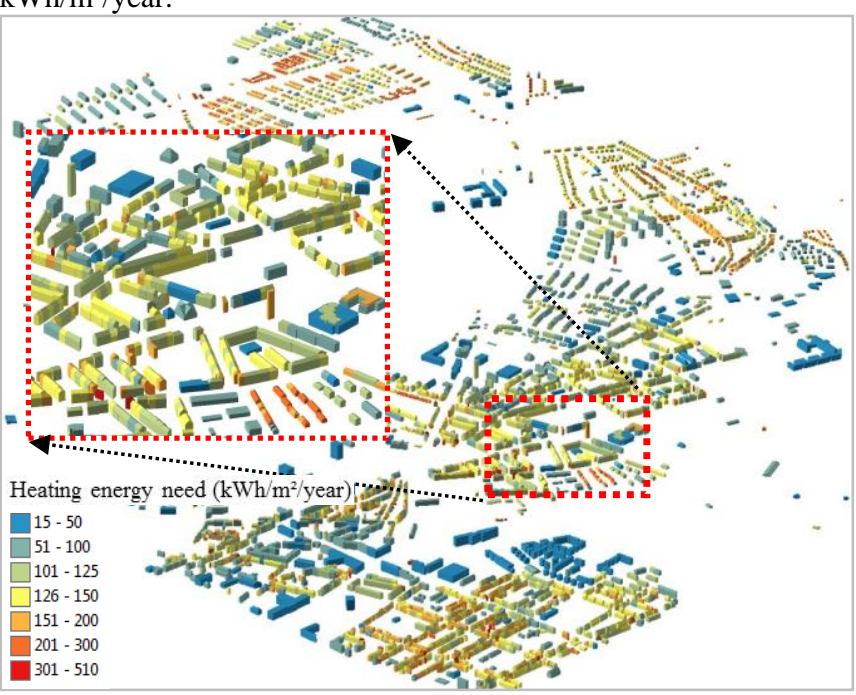

Figure 3. Illustration of heating energy need $\left(\mathrm{kWh} / \mathrm{m}^{2} / \mathrm{year}\right)$ in a district in the city of Karlsruhe in Germany

The yearly specific building energy needs are aggregated according to the building typologies (e.g. type and age) defined in this study. Figure 4 illustrates the total number of buildings (right $y$-axis) in each of the 33 typology and the aggregated 


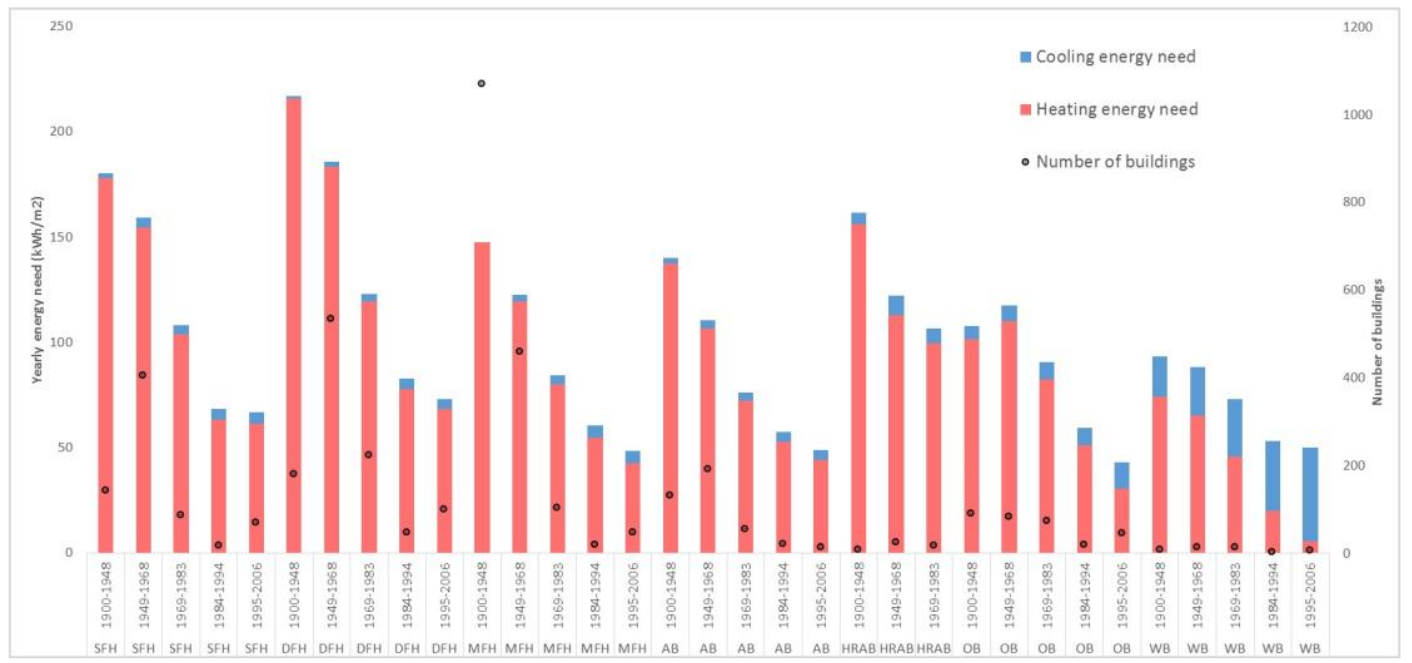

Figure 4. Yearly specific building heating and cooling energy needs in 33 building typologies and corresponding number of buildings in each typology

heating and cooling energy needs (left y-axis). As expected, the heating needs are higher than the cooling needs in most of the building typologies (except the workshop buildings built after 1984). The highest specific heating energy needs are observed in double-family buildings built between 1900 and 1948 and the lowest in office buildings built between 1995 and 2006. In general, the older buildings have higher heating needs whereas the office and workshops buildings (independent of construction year) show higher cooling needs.

(a)

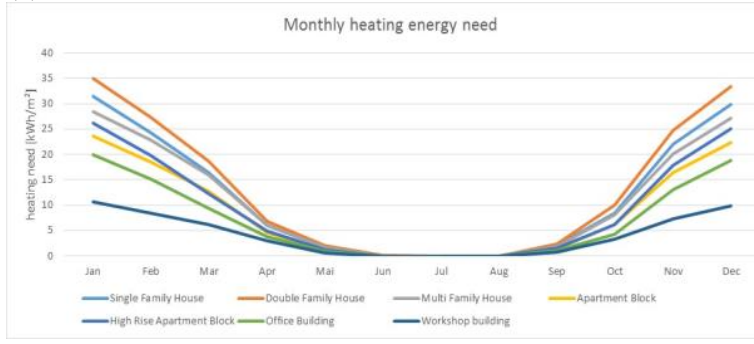

(b)

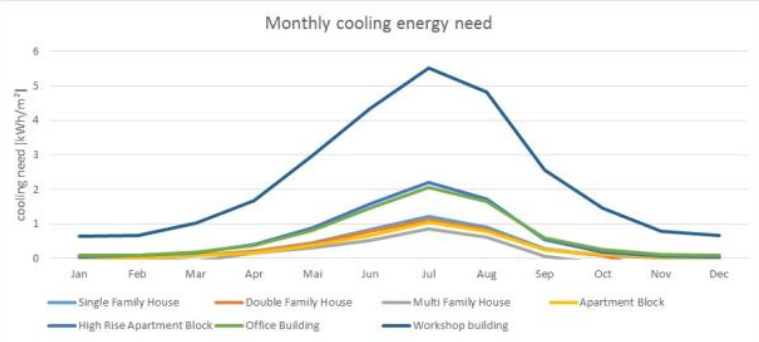

(c)

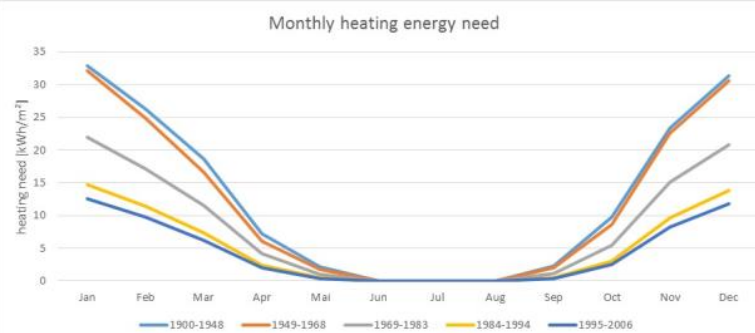

Figure 5. Monthly specific heating and cooling energy needs for 7 building types and 5 age classes
The monthly pattern of the heating and cooling energy needs varies among the 7 building types (Figure 5: a, b). The double family buildings tend to have higher specific heating needs throughout the heating period (October to April) than the other building types. Regarding cooling energy needs, office buildings and high-rise apartment blocks demonstrate similar pattern during cooling months (June to August). The other residential buildings show minimum cooling needs. The older buildings as observed earlier, demonstrate higher specific heating energy needs than those of the recent buildings (Figure 5: c).

\subsection{Model performance}

The CityBEM monthly model is tested in several European and Asian urban cities, with varying number of buildings in both LOD1 and LOD2 data ${ }^{6}$. The multiprocessing package of Python is exploited to improve the computational efficiency of handling of large 3D city models. The model proves very efficient and quick in displaying results in the virtual machine ${ }^{7}$. For example, it takes around 3 minutes to run on about 4300 LOD2 buildings, 8 minutes on 12000 LOD2 buildings, 28 seconds on 600 LOD1 buildings, etc.

\section{VALIDATION APPROACH}

A comprehensive validation of the CityBEM monthly model is performed to justifies its applicability and robustness. At first, a review of the comparative validation results obtained by the different studies implementing the ISO 13970 method is performed. Second, to ensure the correct implementation of the method in python programming interface, the input values and corresponding results suggested in the Annex $\mathrm{J}$ of ISO document (ISO 2008), have been considered in the CityBEM. Finally, the energy needs of an office and a residential building are validated with a dynamic simulation model TRNSYS.

\subsection{Validation of ISO 13970 method in other studies}

ISO developers have internally carried out error estimation and validation of the monthly methods. They concluded that the

${ }^{6}$ LOD1 data of Kuwait, Abu Dhabi was generated from 2D, whereas the LOD2 data of Lyon was collected through personal contact.

${ }^{7}$ Linux server for Python is configured with 64GB Ram, 10 cores HDD, 8.5 GB free and PostgreSQL server with 16GB Ram, 10 cores, 44 GB free. 
monthly calculation gives correct results on an annual basis, but the results for individual months close to the beginning and end of the heating and cooling season can have large relative errors (ISO 2008), p. 15).

Recently, several studies as explained in Table 1, carried out validation of ISO methods with widely used dynamic simulation software such as TRNSYS or EnergyPlus. Kristensen and Petersen (2016) found out that the monthly quasi-steady-state model predicts a lower monthly energy need for space heating and higher monthly energy need for cooling compared to the dynamic model. Zangheri et al. (2014) found that the simplified monthly method tends to over-estimate the energy needs for cooling, especially for office buildings located in a Mediterranean climate. The results obtained by (Vollaro et al. 2014) confirms that the monthly method tend to overestimate and underestimate of approximately $12-14 \%$ the cooling and heating energy demands respectively, compared to the results obtained from the dynamic simulation with TRNSYS. Kim et al. (2013) carried out a deterministic and a stochastic comparison of simple hourly method with the EnergyPlus 6.0 software, with the inputs and boundary conditions for both approaches as close to each other as possible. They found that in the deterministic method, ISO 13970 predicts less annual heating and cooling energy demands than EnergyPlus. In the stochastic approach, EnergyPlus showed higher stochastic robustness than ISO 13790. However, Vartieres et al. (2013) found that the yearly cooling need obtained with the monthly method is almost three times higher than that of TRNSYS. From May to October, the predicted cooling demands by ISO 13790 are smaller than EnergyPlus ones, while in the other months the predicted cooling demands are larger than EnergyPlus (Kim et al. 2013). Earlier Kokogiannakis et al. (2008) confirmed that monthly method demonstrates higher cooling needs than the other methods. The EU study in the ENTRANZE project concluded that heating needs in ISO monthly and hourly are in line with EnergyPlus but the cooling needs are different in some climatic conditions (Zangheri et al. 2014).

Therefore, most of the studies found that the ISO method predicts less heating and more cooling needs, compared to the dynamic simulation software. CityBEM also shows similar patterns of cooling and heating needs (Chapter 4).

\subsection{Validation with ISO 13970 reference}

In order to validate the proper implementation of ISO 13970 method, e.g. use of the model equations, the ISO authors have given some exemplary input data and corresponding results in the Annex $\mathbf{J}$ of the document. Therefore, the robust implementation of the CityBEM model is checked using the exactly the same input values as suggested.

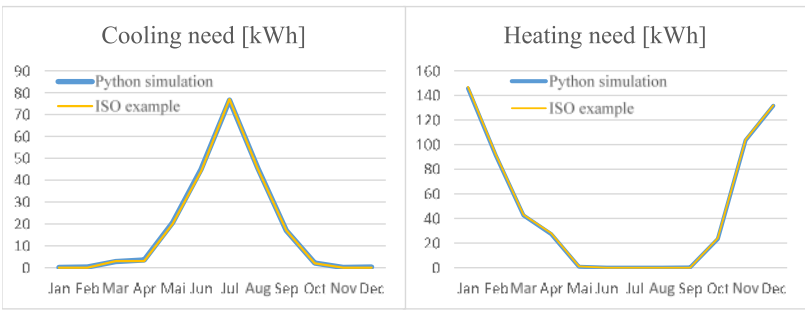

Figure 6. Comparison of energy needs with the assumptions explained in the ISO 13790:2008 (Annex J) for an office building room
A test case consisting of an office building room with only one external wall facing west is considered. Other specific assumptions and simplifications (according to the suggestions) are made for the thermal heat flows and heat gains coefficients calculations. The results obtained by the CityBEM exactly match with the annex results (Figure 6). This justify the proper implementation of the ISO method in CityBEM.

However, in the annex example, not all input data and justifications are presented. Therefore, the validation of the complete model in the python script is not possible.

\subsection{Validation with TRNSYS}

TRNSYS software is used to simulate the behaviour of the transient system (http://www.trnsys.com). The simulations are focused on assessing the performance of thermal and electrical energy systems. In this study, TRNSYS is used to validate the results of the cooling and heating energy needs obtained by the CityBEM. Since TRNSYS cannot perform simulation on multiple buildings at a time, two individual buildings e.g. an office (built in 1975) and a residential building (built in 1985) in Karlsruhe are validated separately, with the same input data and assumptions as chosen in the CityBEM model.

\subsubsection{Preparation of input data}

Several inputs are required in TRNSYS. At first, the two buildings are extracted from the CityGML dataset to calculate the building geometries e.g. surface area of walls, roofs, etc. (Figure 7).

\begin{tabular}{|l|c|}
\hline Surface type & Area [m²] \\
\hline Wall_North & 84.71 \\
\hline Wall_South & 91.39 \\
\hline Wall_East & 82.26 \\
\hline Wall_West & 82.33 \\
\hline Roof_West & 84.71 \\
\hline Roof_East & 84.78 \\
\hline Ground & 129.19 \\
\hline
\end{tabular}

Figure 7. The CityGML building extracted for simulation in TRNSYS and corresponding geometric properties

\begin{tabular}{|l|l|l|l|}
\hline \multicolumn{2}{|l|}{ Parameters } & \multicolumn{1}{|c|}{$\begin{array}{c}\text { Residential } \\
\text { building }\end{array}$} & $\begin{array}{l}\text { Office } \\
\text { building }\end{array}$ \\
\hline \multirow{3}{*}{ Window area $\left(\mathrm{m}^{2}\right)$} & North & $4.47(4.9 \%)$ & $\begin{array}{l}9.27 \\
(10.16 \%)\end{array}$ \\
\cline { 2 - 4 } & South & $\begin{array}{l}11.19 \\
(12.25 \%)\end{array}$ & $8.34(9.13 \%)$ \\
\cline { 2 - 4 } & East & $5.54(6.74 \%)$ & $10.08(12.25)$ \\
\cline { 2 - 4 } & West & $5.54(6.74 \%)$ & $\begin{array}{l}11.39 \\
(13.85 \%)\end{array}$ \\
\hline \multirow{3}{*}{ U values $\left(\mathrm{w} / \mathrm{m}^{2} \mathrm{k}\right)$} & Wall & 0.6 & 1.5 \\
\cline { 2 - 4 } & Roof & 0.4 & 1 \\
\cline { 2 - 4 } & Floor & 0.6 & 1.2 \\
\cline { 2 - 4 } & Window & 2.7 & 2.9 \\
\hline G value [-] bridges & & 0.75 & 0.75 \\
\hline \begin{tabular}{l} 
Thermal $\left[\mathrm{W} / \mathrm{m}^{2} \mathrm{~K}\right]$ \\
\hline Infiltration $\left[\mathrm{h}^{-1]}\right.$
\end{tabular} & 0.1 & 0.15 \\
\hline Ventilation $\left[\mathrm{h}^{-1]}\right.$ & & 0.2 & 0.2 \\
\hline $\begin{array}{l}\text { Internal heat gains } \\
{\left[\mathrm{W} / \mathrm{m}^{2}\right]}\end{array}$ & & 19.4 & 24.7 \\
\hline Set-point temperature & Heating & 20 & 20 \\
\cline { 2 - 4 } & Cooling & 26 & 26 \\
\hline
\end{tabular}

Table 3. Input data of the residential and office building in the TRNSYS simulation software 
Then the building attributes and thermal characteristics (e.g. surfaces areas, thickness and composition of walls, roof and ground layers, etc.) are given as inputs in TRNSYS. Calculation of internal gains are different in both models, therefore, careful attention has been given to ensure the same input of heat gains in both models. For this reason, the internal gain was set considering the table from ISO 7730 as suggested in TRNSYS. Then, the scale was adjusted by considering the monthly aggregated values of the internal heat gains in order to ensure exactly the same inputs in both TRNSYS and CityBEM.

Other parameters such as infiltration, ventilation, etc. are also considered identical in both models. The same Meteonorm weather data (wind speed, average temperature data) is given as an input. However, the TRNSYS software itself calculates the solar gain gains by the solar radiation model internally. An overview of the input datasets in TRNSYS software is given in Table 3 .

\subsubsection{Assumptions}

Several assumptions are made to validate the CityBEM results with the TRNSYS. (a) Consideration of shading factors calculation of solar gain in the CityBEM monthly method considers factors such as: shading reduction factor for external obstacles for the solar effective collecting area of surfaces, and form factor between the building element and the sky. Nevertheless, the irradiation data obtained from solar irradiance model already takes into account shading from external obstacles. Therefore, no shading reduction factor is considered in modelling solar gains in TRNSYS. (b) Averaging internal heat flow - In TABULA's method (http://episcope.eu/ieeproject/tabula) the internal heat flow is equal to $3 \mathrm{~W} / \mathrm{m}^{2}$ for every building type. In the example of ISO (Annex J), the internal heat flow is $20 \mathrm{~W} / \mathrm{m}^{2}$ from 8.00 to 18.00 . So, the time average internal heat flow of $8(=0.4 \times 20) \mathrm{W} / \mathrm{m}^{2}$ is considered in both approaches. This value refers to specific heat gains averaged for a day. (c) Introducing time reduction factors continuous cooling/heating is unrealistic. In order to make a good comparison, the scheduling factors in TRNSYS and in the CityBEM model are defined appropriately by introducing a time reduction factor.

\subsubsection{Discussion of validation results}

Considering all the inputs and assumptions, the ISO 13970 results (CityBEM model) of the heating and cooling energy needs of the residential and office buildings are validated with that of TRNSYS. Figure 8 and Figure 9 illustrate the comparative simulation results of the office building and the residential building, respectively.

For both of the buildings, the order of magnitude and the curve profiles are similar during the cooling and/or heating period in the TRNSYS simulation and the ISO based CityBEM model. The specific heating energy need obtained from the model is very similar to the TRNSYS simulation in different months. The relative error of the yearly heating is between $5 \%$ and $10 \%$. So, the implemented CityBEM monthly model seems to be robust for heating. Concerning cooling energy need, the results obtained by both approaches are quite different. The relative error of the yearly cooling goes from $18 \%$ to $80 \%$. The differences or the uncertainties of the ISO monthly result may lie in the case study region of Karlsruhe, which requires rarely any cooling energy in the summer months. Similar patterns was also observed by (Kokogiannakis et al. 2008). Therefore, it is essential to validate the cooling need in other regions where air conditioning is widely used.

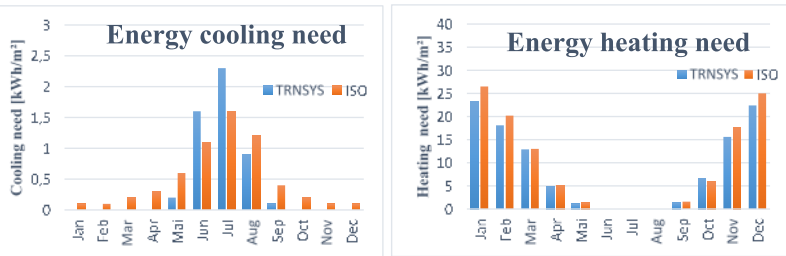

Figure 8. Comparison of energy simulation results obtained with TRNSYS and CityBEM for an office building (1975)
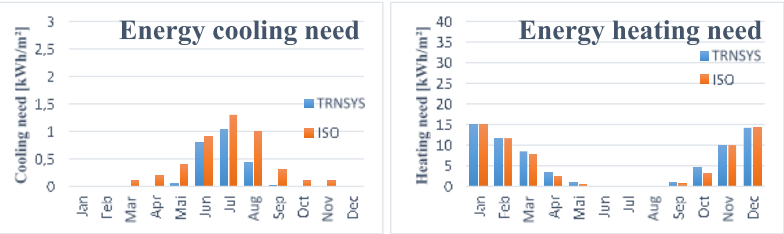

Figure 9. Comparison of energy simulation results obtained with TRNSYS and CityBEM for a residential building (1985)

\section{CONCLUSION}

In this study, the CityBEM monthly model is developed through an open source implementation of the ISO 13970:2008 standard to calculate monthly heating and cooling energy need for a large number of building stocks in a city. It is based on the 3D city models of the CityGML standard and the required input parameter such as the building geometry, typology and energy characteristics have been associated with the 3D data. The model is applied in several urban districts with varying number of buildings stocks, using both LOD1 and LOD2 datasets. The robustness of the model is also tested using a 3-step validation approach. The model can help the decision makers or utility companies to determine the potential energy efficiency in the buildings and thus help in energy planning.

The monthly ISO method has several limitations, which have also been identified in other studies. It is based on steady-state conditions, the variation of parameters such as heat flows and heat transfer coefficient depends on the external temperature which is set to a constant value for each month (Vollaro et al. 2014). Vartieres et al. (2013) concluded that assuming constant temperature with fresh air introduced gives cooling loads during transition months, when introducing outdoor airflow could reduce the temperature. The ventilation airflow supplied from the outside with a smaller averaged external temperature gives heat losses by ventilation even during summer. Moreover, the users and their behaviour play an important role in calculating building energy needs. It was difficult to collect such exact data for each building. Regarding handling of 3D data, we observe geometrical and topological errors in the CityGML dataset which could not be completely imported into the postgresSQL database, resulting in exclusion of some buildings in analysis. Nouvel et al. (2013) and Agugiaro (2016) also explained such uncertainties e.g. geometrical precision, thermal building parameters estimation, etc. Another limitation is that each building is modelled as single zone. With the availability of more detailed building information e.g. LOD4 city models, buildings can be modelled as multi-zones.

The ISO monthly method (and therefore the CityBEM model) can be further improved. For example, Vartieres et al. (2013) suggested introduction of a variable supply air change, by dividing each month into two intervals. Moreover, in calibration of dynamic parameters, different studies carried out a comparison between dynamic simulations and the monthly 
methods, and they all agrees that the loss utilization factor formula is correct in its general equation, and that the numerical coefficient should be better defined for each specific case study. The model can, however, be further improved in future. The energy needs for heating and cooling can be used as an input for the energy balance of the heating and cooling systems and ventilation system in order to calculate the energy use. Hourly and seasonal energy can also be calculated. In this regard, the CityBEM monthly model can also be validated with the hourly method by aggregating the hourly values into months and years. The sensitivity of the critical model input parameters can also be tested in future. Building energy saving potential and further refurbishment priorities/scenarios can be simulated to identify further applications of the model. The model can also be adapted to support more detailed LOD3 or LOD4 datasets. For example, the exact window to wall ratio can be calculated from those datasets, which will improve the modelling results. Finally, a Graphic User Interface (GUI), considering the implemented open source software implementation in the 3D environment could be built to help the decision makers to fulfil the above-mentioned objectives.

\section{ACKNOWLEDGEMENTS}

We are grateful to the city of Karlsruhe for providing the 3D city models and EDF/EIFER for funding the research.

\section{REFERENCES}

Agugiaro, G. (2016) Energy planning tools and CityGML-based $3 \mathrm{D}$ virtual city models: experiences from Trento (Italy). Applied Geomatics, 8, 41-56.

Attia, S. \& A. Ana Muresan. 2015. Romanian Standards for Energy Performance in Buildings Translation of the Romanian Standards for Energy Performance in Buildings. Sustainable Buildings Design Lab.

Bahu, J.-M., A. Koch, E. Kremers \& S. M. Murshed (2014) Towards a 3D spatial urban energy modelling approach. International Journal of 3-D Information Modeling (IJ3DIM), 3, 1-16.

Biljecki, F., J. Stoter, H. Ledoux, S. Zlatanova \& A. Çöltekin (2015) Applications of 3D city models: state of the art review. ISPRS International Journal of Geo-Information, 4, 2842-2889.

Chalal, M. L., M. Benachir, M. White \& R. Shrahily (2016) Energy planning and forecasting approaches for supporting physical improvement strategies in the building sector: A review. Renewable and Sustainable Energy Reviews, 64, 761776.

Corrado, V. \& E. Fabrizio (2007) Assessment of building cooling energy need through a quasi-steady state model: Simplified correlation for gain-loss mismatch. Energy and Buildings, 39, 569-579.

Eicker, U., R. Nouvel, C. Schulte, J. Schumacher \& V. Coors. 2012. 3D Stadtmodelle für die Wärmebedarfberechnung. In Fourth German-Austrian IBPSA Conference. Berlin.

ISO. 2008. Energy performance of buildings - Calculation of energy use for space heating and cooling. In ISO 13970:2008, 162. Geneva, Switzerland: ISO/TC 163/SC 2 Calculation methods.
Kim, Y.-J., S.-H. Yoon \& C.-S. Park (2013) Stochastic comparison between simplified energy calculation and dynamic simulation. Energy and Buildings, 64, 332-342.

Koch, E. A. 2016. Continuous Simulation for Urban Energy Planning Based on a Non-Linear Data-Driven Modelling Approach. In Fakultät für Architektur, Fachgebiet Bauphysik \& Technischer Ausbau. Karlsruher Instituts für Technologie.

Kokogiannakis , G., P. Strachan \& J. Clarke (2008) Comparison of the simplified methods of the ISO 13790 standard and detailed modelling programs in a regulatory context. Journal of Building Performance Simulation, 1, 209-219.

Kristensen, M. H. \& S. Petersen (2016) Choosing the appropriate sensitivity analysis method for building energy model-based investigations. Energy and Buildings, 130, 166176.

Kwak, H.-J., J.-H. Jo \& S.-J. Suh (2015) Evaluation of the Reference Numerical Parameters of the Monthly Method in ISO 13790 Considering S/V Ratio. Sustainability, 7, 767-781.

Mendes, G., C. Ioakimidis \& P. Ferrão (2011) On the planning and analysis of Integrated Community Energy Systems: A review and survey of available tools. Renewable and Sustainable Energy Reviews, 15, 4836-4854.

Nouvel, R., A. Mastrucci, U. Leopold, O. Baume, V. Coors \& U. Eicker (2015) Combining GIS-based statistical and engineering urban heat consumption models: Towards a new framework for multi-scale policy support. Energy and Buildings, 107, 204-212.

Nouvel, R., C. Schulte, U. Eicker, D. Pietruschka \& V. Coors. 2013. CityGML-based 3D city model for energy diagnostics and urban energy policy supports. In 13th Conference of International Building Performance Simulation Association. Chambéry, France.

OGC. 2012. OGC City Geography Markup Language (CityGML) Encoding Standard 2.0.0. Open Geospatial Consortium.

Reinhart, C. F. \& C. C. Davila (2016) Urban building energy modeling-A review of a nascent field. Building and Environment, 97, 196-202.

Sirén, K. \& A. Hasan. 2007. Comparison of two calculation methods used to estimate cooling energy demand and indoor summer temperatures. In Clima 2007 WellBeing Indoors.

Swan, L. G. \& V. I. Ugursal (2009) Modeling of end-use energy consumption in the residential sector: A review of modeling techniques. Renewable and sustainable energy reviews, 13, 1819-1835.

Vartieres, A., A. Berescu \& A. Damian. 2013. Energy demand for cooling an office building. In 11th International Conference on Environment, Ecosystems and Development, 132-135.

Vollaro, R. D. L., C. Guattari, L. Evangelisti, G. Battista, E. Carnielo \& P. Gori (2014) Building energy performance analysis: A case study. Energy and Buildings, 87, 87-94.

Zangheri, P., R. Armani, M. Pietrobon, L. Pagliano, M. F. Boneta \& A. Müller. 2014. Heating and cooling energy demand and loads for building types in different countries of the EU. Report in the frame of the EU project ENTRANZE. 